\title{
Student Perceptions of the Library during Times of Terror: Exploratory Research Surveying Students Affected by the October 1 Shooting and Their Impressions of Safety in the Academic Library Community
}

\section{Kelsey Lupo Mazmanyan}

\begin{abstract}
On October 1, 2017, the history of Las Vegas, Nevada was forever changed when a mass shooting claimed the lives of 58 innocent people at a concert site on the Vegas Strip. Only three miles away, the University of Nevada Las Vegas and its main branch, Lied Library, became a space where students sought shelter and answers. To understand how this event impacted students' perceptions of safety at UNLV, nine qualitative interviews were conducted asking students to consider the various qualities of a public place that make it feel safe. Students' responses were analyzed to determine similarities and differences of "safe" locations on campus. Although each participant shared unique viewpoints as to where they would seek shelter and why, it was discovered that most students did not alter their actions regarding spatial use after the incident. More research must be conducted to determine if the majority of UNLV students feel similarly about their campus spaces and how the university can improve upon feelings of safety in the academic community.
\end{abstract}

On the night of Sunday, October 1, 2017, a man opened fire from above on a crowd at the Route 91 Festival held adjacent to the Mandalay Bay Hotel in Las Vegas, Nevada. A total of 58 people were killed, and hundreds were injured. This attack occurred only three miles away from the University of Nevada Las Vegas' (UNLV) campus and the campus' main library branch, Lied Library, which was fully staffed and occupied like any other night. The shooting took place at roughly 10 p.m.; Students who were in Lied Library at this time learned of the events happening close by, and some did not want to leave the building. As documented in university statements, campus police had determined that the vicinity of UNLV was safe and not under threat. This caused the library and other campus buildings to operate under normal closing procedures, asking everyone in the space to leave by midnight. In the days following the shooting, some students reported that they were afraid to leave the library that night and were frustrated by the decision for the building to close among the chaos. The following morning, UNLV's President released a statement about the incident but chose not to close the school to help create a

* Kelsey Lupo Mazmanyan is a MLIS graduate from Kent State University and Digital Collections Student Supervisor at University of Nevada Las Vegas; email: kelsey.mazmanyan@unlv.edu. C2020 Kelsey Lupo Mazmanyan. 
sense of routine for students and staff alike. In the days that followed, the UNLV community used the spaces of their school to come together, hold vigils, and heal. The event was extraordinarily momentous for the city, the state, and the country; this led the researcher to wonder if the impact of the shooting and the reactions of UNLV as a whole would influence students' perceptions of safety on UNLV's campus and in all public spaces.

In an attempt to gain insight into what makes a community space safe and comforting, especially during an attack like the Route 91 shooting, qualitative data was collected from UNLV students to evaluate their perceptions of safety within the school's main branch library compared to other locations on campus. What measurable features of a shared space make it feel safe, and what can be done to increase that sense of safety? Although the event did not occur on campus, its impact was felt by students and staff of the university and is still discussed to this day. The information found by this research can help shape future library initiatives to reimagine safe and welcoming community spaces, both at UNLV and at other institutions across the country. This study combines a literature review of libraries that have studied various factors contributing to safety, the aftermath of the shooting with regard to campus activities, and qualitative interview data collected from willing student participants at UNLV to paint a realistic portrayal of student perceptions of safety.

Due to the investigative nature of this study and the multitude of questions that could be asked of the participants, the researcher chose to develop three overarching inquiries that would produce the most actionable answers, collected through qualitative interviews:

1. After the October 1 shooting, did students' behaviors change regarding campus and library space use? If so, why?

2. If an act of terrorism occurred near campus in the future, where would students go on campus to feel safe, and why would they go there?

3. What notable design, spatial, interpersonal, or architectural features of a shared space make it feel safe, and can that safety be increased?

Because this research is exploratory by design and uses qualitative methodology, no formal hypothesis was made about the possible outcomes of results. Furthermore, the range of possible answers given by students was too broad and unknown to hypothesize about or generate possible preconceived answers before collecting the data. ${ }^{1}$

\section{Literature Review}

Literature on the topic of student safety casts a wide net over all studies conducted to improve physical safety. However, few studies have attempted to understand the feeling of safety that a place can give or take away depending on its architectural and interpersonal characteristics. Even fewer investigations have been conducted surveying students about their perceived safety in the same localized area where a terrorism event has occurred. There have been many research activities conducted at UNLV or using UNLV's student body regarding the October 1 event, including narrative psychological research surveying victims of the shooting; research preserving websites, tweets, articles, and videos connected to the tragedy; and countless other studies, lectures, and events centered on this catastrophic incident. ${ }^{2}$ Still, no research has yet been connected to UNLV's libraries or has focused on the use of a specific campus space. Thus, previous studies consulted for this literature review have been categorized into four main themes: academic research conducted regarding student safety, anecdotal responses and recommendations to increase safety in spaces that have been affected by terrorism, vari- 
ous methodologies used to measure and increase security or safety in a shared space, and governmental or organizational plans for the creation of terrorism-resistant architecture.

With regard to the first theme, related research has been conducted on two college campuses studying perceptions of safety of their institutional spaces, with an emphasis on areas of high traffic that are often used by students. The first study, conducted by Paul Stretesky and Michael Hogan, focused on female student responses to perceptions of safety on their undescribed New York college campus after hearing about the Columbine High School shootings in Colorado through the media. ${ }^{3}$ Stretesky and Hogan used data collected in 1999 before and after the Columbine shooting for an unrelated study to see if patterns emerged from responses before and after the Columbine event regarding personal safety. While the researchers found that media exposure to the shooting did decrease students' perceptions of safety, the focus of the study and the decision to only involve female participants differs dramatically from this research study's intended focus. The second campus study, conducted at Ohio University in 2007, questioned students' perceptions of safety on campus, the factors that influenced these feelings, and the methods used to protect themselves; researchers hypothesized that gender was the cause of differences between the students. ${ }^{4}$ While some students implied that their gender made them feel more or less safe, the majority of answers from both men and women were very similar regarding how safe they felt on campus, with only slight differences in methods of staying safe. However, the research differs from this current study's focus, as it is the present goal not to determine who feels safest, but where they feel safest and why.

The second theme of literature involves nonresearch case studies of specific libraries that evaluated the safety of their buildings and discussed improvements to be made. Some of the evaluations came about because of a terrorizing event, like a school shooting or national security threat. These articles focused on the ability of a library to be as prepared as possible to handle safety issues while understanding that certain risks are inevitable for large public spaces used by so many people. Recommended library security measures across the nation after the September 11 terrorist attacks in 2001 included bag checks upon entrance to the building, clear exit signs visible across a space, lack of concealment areas indoors and outside the building, and regular evacuation and emergency trainings for library staff. ${ }^{5}$ In another more recent occurrence, library staff at Florida State University spoke of the shooting that occurred in their academic branch in 2014. Staff members stressed the campus' need for more full-time security personnel to be working at all times and for increased active shooter trainings for all individuals working in public places. ${ }^{6}$ Similarly, library staff present for the UCLA shooting in 2016 wrote about the need to better understand rules regarding students entering buildings during campuswide "lockdowns." They also discovered the need to create reliable methods of disseminating emergency information quickly to students and staff, as their current campus system could not be depended on. ${ }^{7}$

Other evaluations did not stem from a particular incident; instead, they focused on architectural components within a building that increase the safety of individuals and/or reduce crime in a space. One study conducted by Jeanne Carey suggested the following measures: staff desks should be spread out across large areas with monitoring desks or stations on all floors of the library, security should be increased on floors that are less crowded during down times, and sight lines should be made clear to all entrances and exits across the space. ${ }^{8}$ In another study, at a Nigerian university library by Oluchi Okere and Abraham Taiwo, alternate methods of security mentioned to reduce library crime included increased video surveil- 
lance of public areas and the use of key cards to restrict access to valuables. ${ }^{9}$ While libraries are becoming more prepared to handle these security scenarios, there is only so much that can be done while still providing service to public patrons. As was mentioned in a disasterprevention manual for a public library, the need to be prepared for all situations, natural and manmade, must be balanced with the responsibility to provide a place of refuge to patrons "during times of crisis." ${ }^{10}$ A library is not meant to be a fortress to keep all things out; it is meant to be a community space where everyone is welcome.

The third theme of literature reviewed encompasses specific, tested research methodologies connected to architectural or spatial design and safety or crime. A study conducted in 1992 by Bonnie Fisher and Jack Nasar studied perceptions of fear related to public spaces that have variances in prospect (open view), refuge (protection), and escape. The research built off Prospect-Refuge Theory previously developed in 1975, arguing that, in addition to these two variables, a third one (escape) is important to people when considering the safety of a place. Interestingly, the research found that perpetrators of crime also prefer these characteristics, drawing insightful and unfortunate connections between victims' perceived safe places and the places that are targeted for crime. ${ }^{11}$ Another older research analysis conducted in 1977 by Robert Mawby studied Defensible Space Theory and its flaws in design. Defensible Space Theory, originally developed by Oscar Newman (who built off earlier works by Jane Jacobs), researched the connections between crime patterns and architectural spaces. The design characteristics that Newman and Jacobs believed had an impact on crime were the following: the clarity of a distinction between public and private spaces; the opportunities for passersby to see incidents and react to them; the number of witnesses present in a "neutral" area; and the general design features that encouraged or discouraged "isolation." ${ }^{12}$ Although Newman's research findings suggested that private, high-rise buildings were more likely to have crimes committed in them, Mawby argued that there were too few samples of this finding to prove reliable and that Newman's research design was flawed. Another more recent research study in this category of literature by Kristin Henrich and Richard Stoddart used a "Crime Prevention through Environmental Design" checklist at the University of Idaho's library to determine the safety of a space using predetermined factors. ${ }^{13}$ The checklist had 10 areas to assess and determined that certain improvements could be made to the space without compromising the already existing structure, including better lighting, closing off entrapment areas to the public, having more signs visible related to areas of accessibility and exits, and increasing staff surveillance of the entire building.

The fourth and final theme of this literature review, plans for the creation of terrorismresistant architecture, felt necessary to include as context for how the United States is combating terrorism through architectural changes. The Federal Emergency Management Agency released a reference manual in 2003 related to the protection of citizens regarding terrorist attacks. ${ }^{14}$ The manual provided context regarding spatial design to consider when making buildings safer but concluded that work still needed to be done in this field before realistic and testable methods could be created. Similarly, in an abstract written in 2007 by Benjamin Thompson and Lawrence Bank, the authors discussed the plethora of procedures written to protect buildings from natural disasters while the need for protection against manmade disasters has undoubtedly increased. ${ }^{15}$ "Performance-based design codes," or PBD codes, were mentioned as a work-in-progress system that may be used in the future to build terrorismresistant spaces, but little information could be found that offers more up-to-date progress. ${ }^{16}$ 
These various articles and previously tested methodologies were reviewed to provide a background understanding of what has been researched regarding perceptions of safety and the scale at which it was studied. There have been very few analyses conducted on college campuses about perceptions of safety, and the researcher found no records of analysis completed on campuses where a local terrorism event occurred in the nearby vicinity. Thus, the present study attempts to fill these gaps and better understand how public spaces are used, perceived, and regarded by students after a localized terror event, with special regard to the methodologies mentioned in the third section of the literature review.

\section{Research Methodology}

Due to the recentness of the event and the investigative nature of the study, the researcher decided to conduct semistructured interviews asking qualitative questions to obtain thoughtful and potentially unique answers from participants. ${ }^{17}$ These open-ended inquiries collected purposeful, powerful data about UNLV students' use of Lied Library compared to other campus locations, as well as their thought processes and reasoning related to finding safe spaces on campus. The questions posed were sensitive in nature and required students to recall a local, traumatic event; for this reason, IRB approval was required before interviewing could begin. This qualitative investigation was created as a culminating experience assignment before completion of the researcher's MLIS degree; thus, it had external deadlines for completion: data collection was to be completed in the summer of 2018, and all research analysis and documentation was to be completed before the end of the 2018 calendar year.

By encouraging students to speak for themselves, the answers they provided were more meaningful and organic than if they were to provide prefixed answers in a multiple-choice questionnaire. Furthermore, because this study is exploratory and allowed students to respond at varying lengths to the research questions, the participants' responses help to create a starting point in understanding how students perceive safety on campus. The goal for this research study was to interview approximately 10 students during the months of July and August 2018; because this study is qualitative, had a time-sensitive deadline, and would require manual transcription, the researcher felt that this number would be optimal for data collection, analysis, and to best understand how students interpreted the open-ended research questions. In total, nine participants were interviewed, which allowed unique responses to be captured while also showing saturation of certain shared ideas. UNLV has yet again been reported as one of the most diverse undergraduate college campuses in the country, making the participant pool and their responses all the more interesting to analyze. ${ }^{18}$ The researcher made connections with various librarians and campus partners to locate interested student parties who were willing to participate in this study. Library student employee supervisors were contacted and asked to assist with recruitment email distribution to inform students who work for the library about this research and to encourage them to pass along the information to their peers. Additionally, the recruitment email was printed in a flyer format and was posted in various advising and communal areas across campus to attract students. Finally, a small number of deans and supervisors in advising offices were willing to distribute the recruitment email to their student list, further spreading information about how to participate in the research. These varied methods were taken to diversify the participant pool as much as possible

and to become visible to students regardless of their connections to the library. All in all, nine students responded to these recruitment tactics: five students who worked for the library and 
four students who did not. Their ages ranged from 19 to 31, and the participants self-identified with six different ethnicities. While the number of participants is low, the researcher felt that the type of study being conducted (exploratory and qualitative with transcription) as well as the sensitive nature of the research topic (a local shooting) lent itself to a smaller sample size of participants. As the results will later demonstrate, certain inquiries produced consensus and saturation among the students. Furthermore, the nearly 50/50 dichotomy between students employed and not employed by the library was one that the researcher was eager to explore; would students who consider the library their place of employment feel more or less safe in it than students who use the library only for educational or recreational purposes?

\begin{tabular}{|l|l|l|l|l|}
\hline \multicolumn{5}{|c|}{$\begin{array}{l}\text { TABLE 1 } \\
\text { Participant Demography }\end{array}$} \\
\hline $\begin{array}{l}\text { Age } \\
\text { Range }\end{array}$ & $\begin{array}{l}\text { Genders } \\
\text { Represented } \\
\text { (Self-described) }\end{array}$ & $\begin{array}{l}\text { Ethnicities Represented } \\
\text { (Self-described) }\end{array}$ & Year in School & $\begin{array}{l}\text { Work for } \\
\text { University } \\
\text { Libraries }\end{array}$ \\
\hline $19-31$ & 5 Male & $\begin{array}{l}\text { White/Caucasian, Black/ } \\
\text { African American, } \\
\text { Hispanic, Spanish, Native } \\
\text { American, Brazilian }\end{array}$ & $\begin{array}{l}\text { 1 Sophomore } \\
\text { 3 Juniors } \\
\text { 2 Seniors } \\
\text { 1 Recent Graduate } \\
\text { 2 Graduate Students }\end{array}$ & $\begin{array}{l}5 \text { Yes } \\
4 \text { No }\end{array}$ \\
\hline
\end{tabular}

Interviews were set during library business hours at the convenience of the participants' schedules. They were held in a library meeting room reserved by the researcher and lasted 30-45 minutes from setup to completion. The researcher recorded the interviews for later transcription. All students were asked the same questions, with the researcher asking additional clarifying questions only if participants' responses were unclear. For the purposes of this research, the following definition of "safe" was provided to students at the start of their interview: "protected from or not exposed to danger or risk; not likely to be harmed or lost."19 This definition was provided to participants before questions about safety were asked to establish a baseline for how this abstract idea could be interpreted. Once the interviews were complete, students were provided with a gift card as compensation for their participation, as well as campus resource information, including details about on-campus counseling and instructions on how to sign up for UNLV's Emergency Notification System. Interviews were transcribed and later converted into spreadsheet format for ease of response comparison; once the transcription was made, names of students and other identified parties were changed to protect confidentiality, and the audio recording was deleted.

Two separate content analysis techniques were used to understand participants' responses: conventional content analysis and summative content analysis. Conventional content analysis avoids precreating coding categories and instead "allow[s] the categories and names for categories to flow from the data." ${ }^{20}$ Hence, the researcher first adopted this analysis technique by assigning organic, lingual codes to each students' sentences to find patterns among participants' responses. The codes were not predetermined in advance and were instead grounded in students' particular word choices and the meanings or implications of these choices. Summative content analysis is a two-fold technique to understand how often specific words or phrases are used and, more important, to explore the meanings behind their particular uses. ${ }^{21}$ 
This type of content analysis was used next to explore the number of times that participants referred to certain ideas, such as fear or seeking shelter, as well as the context with which they used these words to infer meaning. Because the researcher created this exploratory study as a graduation requirement, they were the only individual allowed to review and analyze the data and thus were the only coder; this limitation of potential word interpretations and codes is understood by the researcher. The assigned codes for each participant's responses were then counted and compared via pivot tables.

\section{Results and Discussion}

The amount of information collected during the nine participant interviews was insightful albeit overwhelming to categorize and make meanings of. The results of each response encompassed many interesting and at times contradictory feelings among students, all of which will be described in the following section. Because participants' replies were qualitative and open-ended, the researcher attempted to code each response to establish patterns between an individual's response to each question as well as across participants with all given interview responses. Results were divided into two categories: those that directly answered the posed research questions and those that revealed themselves spontaneously and could be fodder for future research.

First, to address the research questions posed, we return to the three main inquiries:

1. After the October 1 shooting, did students' behaviors change regarding campus and library space use? If so, why?

2. If an act of terrorism occurred near campus in the future, where would students go on campus to feel safe, and why would they go there?

3. What notable design, spatial, interpersonal, or architectural features of a shared space make it feel safe, and can that safety be increased?

With regard to the first inquiry, the researcher asked baseline questions to understand where students spent the majority of their time on campus, if they remembered altering their behavior in the days following the shooting regarding these spaces, and why their behavior did or did not change. Seven of the nine students reported spending some of their time at Lied Library, UNLV's main branch library centrally located on campus. All nine students reported that their use of the library after the October 1 shooting did not change whatsoever. Reasons why included financial and scholarly obligations to return to the library (especially for the students who are employed there) along with the desire to return to their routines for normalcy. Some students also mentioned that they felt the incident could not have been prevented, which caused them to use the space as they normally would. Despite students verbalizing their concerns about the campus' decision to stay open in the days following the shooting, their behaviors primarily suggested desires that aligned with the university: the need for routine after a tragedy is welcomed; familiarity can be comforting in times of sorrow and confusion. ${ }^{22}$

To compare library use and other areas on campus, participants were asked for other locations where they spent their time and whether or not their use of these spaces changed after October 1. Six of the nine students mentioned spending time in the Student Union, another centrally located communal building, and the remaining locations mentioned were specific to the individual and revealed no other patterns. Six of the nine students reported that their behavior did not change with use of these spaces after the incident, while three did change 
their behaviors temporarily. Again, no patterns could be determined as to why routines changed for some in the greater context of the campus, but a few of the factors that influenced participants' decision-making included whether or not they had connections to concert goers who were in danger on October 1, how accommodating their supervisors and professors were with canceling work shifts and classes the following week, and whether or not they agreed with the campus' and library's reactions to the incident. Comparing these responses, it would seem that some students altered their behavior when considering the massive public space of campus as a whole but did not alter their behavior when using an indoor campus space with resources and places to congregate.

The second research question asked participants to plan ahead rather than recalling the past: if an act of terrorism occurred near campus in the future, where would students go on campus to feel safe, and why would they go there? Again, students' responses ranged in location, as each student chose multiple areas that were familiar to them. When asked outright if

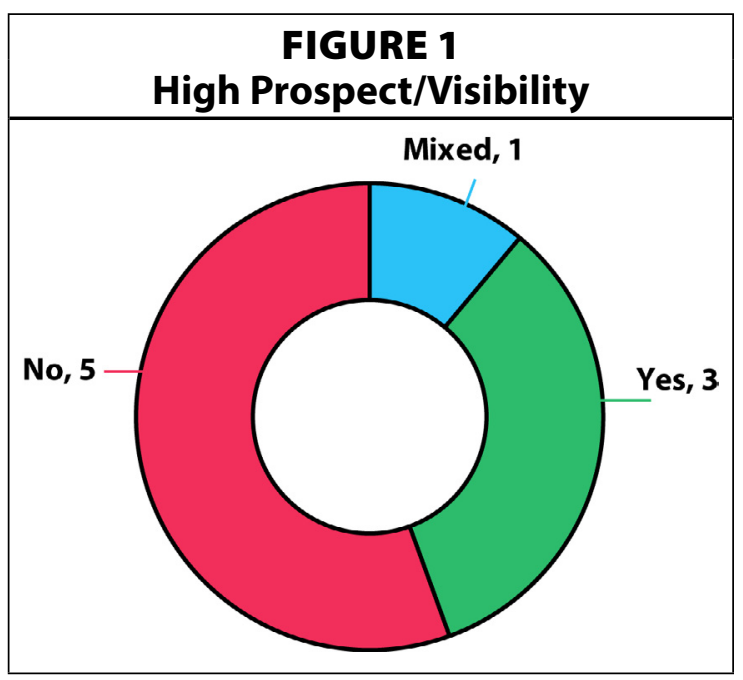
students would choose Lied Library as a safe place to go during an external threat, only one student said "yes," despite five of the participants actively working for the library and spending a majority of their time there. In a more general sense, four of the nine students mentioned that they'd look for a place where doors could be locked behind them, and seven of the nine mentioned they would prioritize looking for an area that gave physical shelter or an area that could lead them to their vehicle where they could make an escape off campus altogether. These responses were compared with the general question of where students feel the safest on campus and why. For each student, the "why" response varied. Students reported feeling safe in areas they were most familiar with, in areas where campus police were known to patrol, and in areas with fewer entrances and more ways to lock themselves into the space.

This led into the discussion with each participant about Prospect Refuge Theory, asking each student to consider their chosen "safe place" within the context of visibility, places to hide, and places to escape. ${ }^{23}$ Although the literature suggested that participants would feel safest in areas with high prospect/visibility of their surroundings, only three of the nine students chose safe places that had any sort of "view."

In fact, of the six remaining students who responded, four of them reported that the area they chose offered no view at all to their surroundings, essentially blocking them from any external contact and deterring them from leaving that safe place because the outside circumstances would be unknown. Participant responses related to the

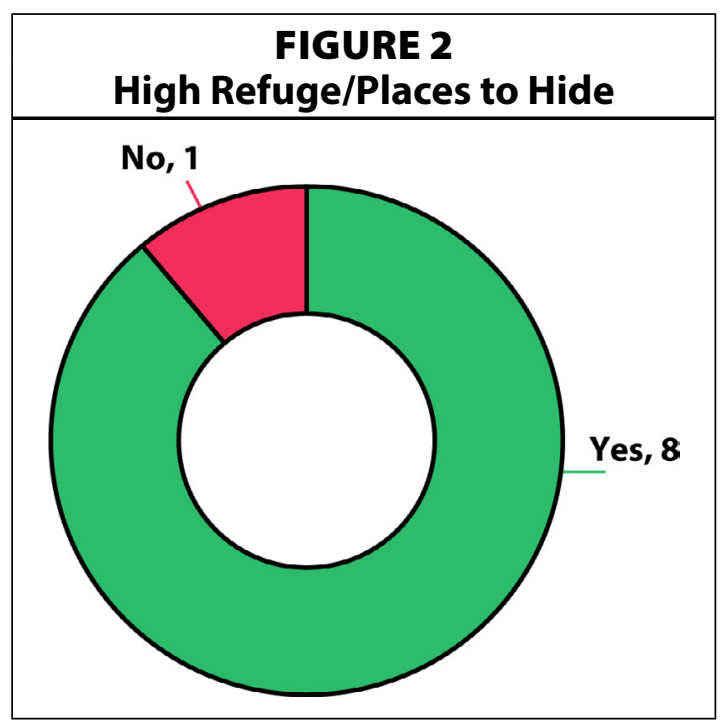




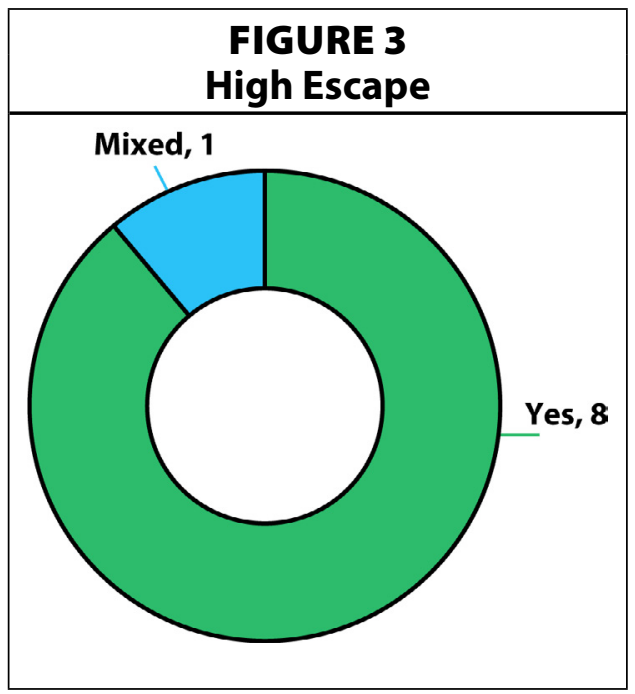

other two aspects of the mentioned theory, refuge and escape, both fell into line with previous studies: eight of the nine students chose locations with many places to hide and multiple escape routes.

Further analyzing students' responses in comparison to Defensible Space Theory, the results were quite mixed; this theory argues that certain architectural and spatial components of a place make it less likely to have crimes committed in it. ${ }^{24}$ If there are numerous witnesses, the spot is less isolated overall, and the space is clearly public, the theory suggests that fewer crimes would be committed there and the space would henceforth be considered "safe." Some student participants in the present research study felt that they'd seek out areas with more people for this very reason, while others felt that more inconspicuous and deserted places would be safer because they believed terrorism occurs in areas with higher traffic. As one participant put it bluntly, "People are a variable that I can't control, and people are stupid... You tell them 'Don't run' and they run... I'm not going [to] leave my personal safety up to people I don't know" (Student 4, Interview).

The final research question asked students what features were important when considering a safe space and inquired if safety in already constructed spaces could be increased. When asked if Lied could be made safer, seven of the nine participants reported yes, with the remaining two students having mixed feelings. Some of the suggestions to increase both physical and perceived safety of the library involved a greater security presence within the building, either by library security staff or campus police, installing metal detectors at the entrances that could detect weaponry, and increasing overall surveillance by trained professionals rather than by security student assistants. A few participants also mentioned that they'd prefer if the library was not open to the public and was only usable by students and faculty to lessen the number of "homeless" individuals in the space.

The remaining results discovered were not tied to specific research questions but revealed themselves throughout various participants' interviews. They are included not because they provide answers but instead because they create more questions and could each become topics of research on their own. These responses are categorized into three groups: linguistic choices, perceptions related to the researcher's word choice, and motivations for participating in the study.

With respect to the first category, linguistic choices, participants' word choices are worth noting because they paint a picture of perception that no survey or questionnaire could match. During the interviews, students were asked how they might react if they were in a public location where gun violence was occurring. Four students brought up the idea of "attacking the gunman," with two of those four saying they believed they would react in this way if they were close enough to the shooter. Interestingly, three of the nine students commented on how they believe they "should" respond compared to how they really would respond, thus internally categorizing their behavior as less brave. To quote one student: 
It's very easy for people to say 'Oh I would try to... attack the gunman and try to make sure that others are safe;' and I'd like to think that that's what I would do too. I think I would just react normally and be in fear and try to run (Student 2, Interview).

Other notable responses included the mention of concealed carry weaponry by three students, with two of the three acknowledging this as being a "hot button" or "hotly debated" issue, and the level of trust that students had for the library after it closed at its normal time on the night of October 1 (Students $4 \&$ 9, Interview). Some students were angry by the lack of communication between the campus and students via the Emergency Notification System, with two students commenting that they were "disappointed" in the system. One participant commented, "Our school did not even notify the students what was happening... they didn't even tell us to stay inside" (Student 7, Interview). Similarly, when asking about the safety of the library, one individual mentioned the trust that was lost that night on October 1. In response to the library's decision to close that night, they said:

It made me feel a bit unsafe. They locked out a lot of students when that was happening. In harsh situations, they may disregard how people feel; a lot of people felt like they could be safe if they had just stayed in a little bit after closing hours, and the library refused to do that for them. If I really needed it, I don't know if I would trust the library (Student 2, Interview).

This reaction is what the library feared would be the outspoken norm across the student body. Most fascinating to discover was the difference in these sentiments between the students who work for the library and those who do not. Most negative feelings about the library's and/or campus' reactions came from library student employee participants, while most nonemployee participants never breached the topic. Perhaps the issue the library was worried about less revolves around student perceptions and instead was more of a blow to staff morale.

The second category of interesting responses connects to the ways that students interpreted words chosen by the researcher during their interviews. For example, two of the interview questions at the beginning of the session asked whether or not the participant had been a victim of gun violence or if they know others who had been victims of gun violence. For the latter, eight of the nine students reported that they knew someone who had been in a situation where gun violence had occurred. Of those eight, only two spoke of their connections to concert goers at the Route 91 Festival; the remaining six spoke of other incidents they were aware of where guns had been involved in a social or family-related situation. However, later in the questioning, two of those same six participants revealed that they did know of someone who was at the concert. This discovery is interesting, because it begs the questions: why did the phrase "gun violence" not trigger these individuals to think of the Route 91 Festival shooting? What does "gun violence" mean in the context of a public shooting?

Later in the interviews, the students were asked to consider where they might go if an act of terrorism occurred near campus and they needed to get to a safe place quickly. While many of the students did take pause before responding, a few students questioned what type of terrorism the researcher was referring to. One student responded that their selection of 
safe place would be different if it was a shooting versus a bomb. Another student asked, "An act of terrorism, like an active shooting or something like that? ... because terrorism, I think of explosives, and that's even worse than gunshots" (Student 8, Interview). This response is curious and worth exploring further, as it calls into question what people perceive to be a terrorist threat and how they might in turn respond to the threat differently, both in the moment and afterward.

The third and final observation made during analysis of participants' responses comes from understanding students' motivations for participating in the study. As is the case for most studies, both qualitative and quantitative, voluntary participants often have a vested interest in the results. When the interviews were being set up, students offered varying levels of information regarding why they'd like to be interviewed. Some felt the topic being covered was important and they'd like to speak out. Others enjoyed having something to do and be part of over the summer while their course load was lighter.

There were, however, a few participants who had explicitly stated motivations. One student was active in the UNLV campus and library community. When responding to the recruitment emails and flyers, they weren't sure if their responses would be welcomed and wanted to be up front that their participation would be colored with information to show that $\mathrm{UNLV}$ is a safe campus, as they are part of the effort to make it so. Once reassuring them that their thoughts, regardless of motivation, would be heard, they participated and still interestingly revealed that many of their sentiments were similar to fellow research participants. On the opposite end of the spectrum, another participant made the researcher aware ahead of time that they wanted to share their story of how unsafe UNLV's campus was to warn other students. This individual was attacked on campus the previous year by an assailant. Although they were able to get away to safety, the participant felt that campus police did not do enough to warn students of this threat. As they explained, "[UNLV Police] didn't catch him until he did something else, and they didn't even notify anybody until he actually committed a crime that was very... violent" (Student 7, Interview). This "violent" crime the student referred to was the sexual assault and rape of another student, a horrific crime where the culprit was later apprehended.

In addition to these students' testimonies, some students had motivations that were not quite forthright but are still noteworthy. Two of the three students who mentioned positive feelings for concealed-carry weapons were law students. One student in particular had many noteworthy responses, including their feeling "like a sitting duck" on campus without their concealed-carry weapon and how much safer they'd feel if they were allowed to carry it on campus (Student 4, Interview). In the state of Nevada, it is currently prohibited to carry concealed weapons on school properties. ${ }^{25}$ This same participant was quoted previously as not trusting people as they are "a variable that I can't control," making their concealed-carry statements and the associated consequences an ironic contradiction that perhaps they could not recognize; the student both wanted to carry a weapon on campus to protect themselves and verbalized concern at not being able to control the emotional actions of others (who also could be carrying weapons). These variations in opinions by research participants were not always so starkly contrasting, but when comparing the nine student participants' experiences and revealing their thoughts and motivations, it is intriguing to witness how many variations there are in the perceptions of safety based on one's previous experiences. 


\section{Conclusion}

The data collected in this research study are detailed and complex, but they barely scratch the surface of fully understanding the nature of students' perceptions of safety in public spaces. The three main research questions were answered: Students' behavior did not dramatically change regarding campus or library spatial use after the October 1 shooting, with the main reasoning described as an attempt to maintain routines to move forward from the tragedy. When asked where students would go for safety purposes if another act of terrorism were to occur, responses varied greatly, with many students choosing locations that had locked doors or areas with which they were most familiar. Finally, when asked what particular features of a place made it feel most safe, students chose areas that offered many places for them to hide/ seek refuge and offered multiple ways to escape. Although students commented that Lied Library did offer many places for students to hide in the event of an emergency, some felt that its central location and likelihood of attracting many students would deter them from seeking shelter there. To glean an accurate sense of UNLV's student body, more research should be done to discover if the nine participants in this study accurately reflect the 30,000+ students who call UNLV home. These same types of questions could be replicated in other university studies, helping to discover if perceptions of safety are geographically linked or if similar responses are given regardless of the location.

\section{Acknowledgments}

The researcher would like to thank their family and colleagues who provided constant support during this (at times) difficult research project and the anonymous reviewers who gave helpful advice to improve this article.

\section{Notes}

1. Lynn S. Connaway and Marie L. Radford, Research Methods in Library and Information Science, 6th ed. (Santa Barbara, CA: Libraries Unlimited, 2017).

2. Jason Scavone, "The Lessons of Tragedy" (Sept. 25, 2018), available online at https://www.unlv.edu/news/ article/lessons-tragedy [accessed 4 February 2019].

3. Paul B. Stretesky and Michael J. Hogan, "Columbine and Student Perceptions of Safety: A Quasi-Experimental Study," Journal of Criminal Justice 29, no. 5 (2001): 429-43.

4. Sarah Starkweather, "Gender, Perceptions of Safety and Strategic Responses among Ohio University Students," Gender, Place \& Culture 14, no. 3 (2007): 355-70.

5. Brian J. Kenney, “Central Libraries in Uncertain Times," Library Journal 126, no. 19 (2001): 36-37.

6. Julia Zimmerman and Susannah C. Miller, "Shooting at Florida State University Libraries: The Act, Aftermath, and Response," Research Library Issues 289 (2016): 5-27, available online at http://publications.arl.org/ rli289/ [accessed 11 April 2018].

7. Virginia Steel, “Thinking about the Unthinkable: A Personal Reflection on the June 1 Incident at UCLA and Library Responses and Roles in Active Shooter Situations," Research Library Issues 289 (2016): 28-37, available online at http://publications.arl.org/rli289/ [accessed 11 April 2018].

8. Jeanne Carey, "Library Security by Design," Library \& Archival Security 21, no. 2 (2008): 129-40.

9. Oluchi O. Okere and Abraham A. Taiwo, "The Role of Architecture and Design in the Security Strategy of a Nigerian University Library," Library \& Archival Security 24, no. 1 (2011): 9-18.

10. Deborah Halsted, Shari Clifton, and Daniel Wilson, Library as Safe Haven: Disaster Planning, Response, and Recovery: A How-to-do-it Manual for Librarians (Chicago, IL: American Library Association/Neal-Schuman, 2014).

11. Bonnie S. Fisher and Jack L. Nasar, "Fear of Crime in Relation to Three Exterior Site Features: Prospect, Refuge, and Escape," Environment and Behavior 24, no.1 (1992): 35-65.

12. Robert I. Mawby, “Defensible Space: A Theoretical and Empirical Appraisal," Urban Studies 14, no. 2 (1977): $169-79$. 
13. Kristin J. Henrich and Richard A. Stoddart, “Library Safety through Design: Using a Checklist Approach at the University of Idaho," Journal of Library Administration 56, no. 7 (2016): 777-89.

14. United States Federal Emergency Management Agency, "After an Incident: Planning for Recovery," in Preparing for Mass Casualty Incidents: A Guide for Schools, Higher Education, and Houses of Worship, available online at https://emilms.fema.gov/IS360/indexMenu.htm [accessed 9 April 2018].

15. Benjamin Thompson and Lawrence Bank, "Risk Perception in Performance-Based Building Design and Applications to Terrorism-Resistant Design [Abstract]," Journal of Performance of Constructed Facilities 21, no. 1 (2007): 61-69.

16. Thompson and Bank, "Risk Perception in Performance-Based Building Design and Applications to Terrorism-Resistant Design."

17. Connaway and Radford, Research Methods in Library and Information Science.

18. U.S. News and World Report, "Campus Ethnic Diversity," in National Universities (2019), available online at https://www.usnews.com/best-colleges/rankings/national-universities/campus-ethnic-diversity [accessed 4 February 2019].

19. Oxford University Press, “Definition of Safe in English” (2019), available online at https://en.oxforddictionaries. com/definition/safe [accessed 25 May 2018].

20. Hsiu-Fang Hsieh and Sarah E. Shannon, "Three Approaches to Qualitative Content Analysis," Qualitative Health Research 15 no. 9 (2005): 1277-88.

21. Hsieh and Shannon, "Three Approaches to Qualitative Content Analysis."

22. United States Federal Emergency Management Agency, Reference Manual to Mitigate Potential Terrorist Attacks against Buildings Providing Protection to People and Buildings: Risk Management Series (Washington, DC: Federal Emergency Management Agency, 2003).

23. Fisher and Nasar, "Fear of Crime in Relation to Three Exterior Site Features."

24. Mawby, "Defensible Space."

25. National Conference of State Legislatures, "Guns on Campus: Overview" (2018), available online at www. ncsl.org/research/education/guns-on-campus-overview.aspx [accessed 5 February 2019]. 